\title{
Errors of retarded and nonretarded subjects by learning stage
}

CLIFFORD J. DREW and WALTER R. BERARD, The University of Texas at Austin, Austin, Tex. 78712

Errors committed by retarded and nonretarded Ss on an associative learning task were classified into four types: extralist intrusions (ELIs), omissions (OMs), stimulus intrusions (SIs), and misplaced responses (MPRs). Mean error types were compared over stages of learning. Results indicated a significant interaction between $S$ classification, error type, and stage of learning. $S$ classification differences were evident only in ELIs (first trial block) and MPRs (first and second trial block). Data suggested considerable overlap between task orientation processes and response learning stage.

To date, verbal learning research with the mentally retarded has focused primarily on gross acquisition-rate questions. Only recently have attempts been made to analyze the learning process in order to identify the components involved in the retardate acquisition deficit. Extralist intrusion (ELI) rates have indicated a less efficient functioning of Underwood \& Schulz's (1960) selector mechanism in the retardate (Drew \& Logan, in press). ELIs, however, have generally comprised a very small portion of the total errors made during associative learning (Drew \& Logan, in press; Kellas \& Baumeister, 1969; Underwood, 1964). This would indicate that reduction of other sources of errors promises greater potential for improving learning than reducing ELIs.

Kellas \& Baumeister (1969) cite support for Underwood \& Schulz's (1960) two-stage learning model in their analysis of retardate errors. These investigators note omissions (OMs) as the major source of low performance in early learning but decreasing in later learning and being replaced by misplaced responses (MPRs). Retardate acquisition curves differ from nonretardates' primarily in early stages of learning (Prehm, 1968). From this it might be expected that different stages of learning would be characterized by different rates and types of errors for retarded and nonretarded Ss. The purpose of the present study was to map the contribution of error sources for retarded and nonretarded $S s$ as a function of the stage of learning.

\section{SUBJECTS}

Twenty-four mentally retarded Ss (IQs
55 to 72 ) and 24 Ss with IQs 100 to 115 were selected randomly from a population of students with CAs 10-3 to 12-4 enrolled in public school classes in Portland, Oregon. Table 1 summarizes CA, MA, and IQ characteristics of the sample. Prior to sampling, Ss having evidence of marked hearing, visual, CNS, or emotional impairments were eliminated from the $S$ pool. Pupil health records and teacher conferences provided information regarding such impairments. MATERIALS

Materials for this study were 14 pairs of words selected from the Palermo \& Jenkins list (1964). Precaution was exercised in pair selection to minimize same or rhyming initial letters and sounds, and rhyming words both within and between stimulus and response elements. Responses were chosen on the basis of the word in Palermo and Jenkins having the lowest associative strength for a given stimulus. Sixth-grade norms in Palermo \& Jenkins (1964) were used to establish associative strength. Stimulus and response components were printed in 24-point black sans serif type letters on $4 \times 6$ in. white cards.

\section{PROCEDURE}

Ss were individually tested in a small room within their respective schools, which was specifically assigned to avoid interruption. It was required that the room be set apart from ongoing building traffic and have doors and windows that could be closed during the experimental sessions. Ss were pretested with $E$ presenting each word in the list, individually printed on a $3 \times 5$ in. white card, for the $S$ to read. This assured that the words used in the paired-associate list were in his sight vocabulary. Five Ss unable to read aloud each word in the $5 \mathrm{sec}$ allotted per word were eliminated from the $S$ pool.

Ss successfully completing the pretest received standardized instructions to read aloud each word on the PA cards and attempt to remember which words were paired. Atter this initial rehearsal of $5 \mathrm{sec}$ per pair. E shuffled the cards and proceeded with the testing. Each stimulus was presented with a maximum exposure of $5 \mathrm{sec}$ (less if $\mathrm{S}$ responded prior to the $5 \cdot \sec$ limit) and a 15 sec interval between entire-list trials. Ss pronounced the responses and were trained to a criterion of three correct responses per pair using the method of adjusted learning (Gillette, 1936). To control for possible serial effect, $E$ shuffled cards remaining in the list during each 15 -sec intertrial interval. \section{RESULTS}

Data were analyzed using a 2 by 4 by 3 (S Classification by Error Types by Trial Blocks) "mixed" analysis of variance design with repeated measures (Winer, 1962). Number of errors by type (ELI, OM, MPR, SI) served as the criterion measure. Table 2 summarizes S's mean errors. Results of the analysis indicated a significant second-order interaction involving all three factors $(F=4.229$, $p<.05, d f=6 / 368)$. This finding prompted further analysis using Tukey's Method a (Winer, 1962).

Inspection of Fig. 1 indicates that the second-order interaction was evident because of the difference in error source contribution as a function of $S$ classification over trial blocks. More ELIs were present in the errors made by retardates than nonretardates in the first block of trials $(p<.01)$. ELIs did not differ significantly between $S$ classification on Blocks 2 and 3 . The number of retarded ELIs decreased significantly $(p<.01)$ from Block 1 to Block 2, while nonretardates' ELIs decreased nonsignificantly $(p>.05)$. ELI rate did decrease significantly from Block 2 to Block 3 for either s classification.

OMs represented the highest frequency error committed by both groups of Ss throughout all blocks of trials. S classifications did not differ significar ly in mean OM rate in any of the thr trial blocks. OMs decreased significal iy for $r$ both $S$ groups from Block 1 to Block 2 $(p<.01)$. OMs did not decrease significantly from Block 2 to Block 3 for either $\mathbf{S}$ classification.

Retardates and nonretardates did not

Table 1

Subject Chronological Age, Mental Age, and IQ Characteristics

\begin{tabular}{llllll}
\hline Group & N & Stistic & $\begin{array}{c}\text { CA } \\
\text { (Months) }\end{array}$ & $\begin{array}{c}\text { MA } \\
\text { (Months) }\end{array}$ & IQ* $^{*}$ \\
\hline \multirow{2}{*}{ Retarded } & 24 & Range & $132-148$ & $74-103$ & $55-72$ \\
& & Mean & 143.66 & 93.79 & 67.25 \\
Nonretarded & 24 & Range & $123-147$ & $126-169$ & $100-115$ \\
& & Mean & 137.00 & 151.37 & 107.37 \\
\hline
\end{tabular}

*Intelligence test varies. Twenty-three of the retarded Ss were tested with the WISC and one with the S-B form LM. Normal Ss were primarily tested with the Kuhlmann-Anderson, except for one who was tested with the WISC and one whose $I Q$ was estimated using group mean and the $S$ 's $C A$. 
Table 2

Retarded and Nonretarded Subjects' Mean Errors by Source and Learning Stage

Subject

Classification

\begin{tabular}{llrrr} 
& Extralist Intrusions & 4.875 & 1.250 & .458 \\
Retarded & Omissions & 17.250 & 5.041 & 2.875 \\
& Stimulus Intrusions & 2.083 & .250 & .250 \\
& Misplaced Response & 10.041 & 4.875 & 2.250 \\
Nonretarded & Extralist Intrusions & .750 & .166 & 0.000 \\
& Omissions & 17.208 & 3.916 & 1.083 \\
& Stimulus Intrusions & 1.375 & .125 & .041 \\
\hline
\end{tabular}

differ significantly in terms of SIs $(p>.05)$. Neither group evidenced a significant decrease in SI over trial blocks ( $p>.05$ ).

Retardates misplaced significantly more responses than did nonretardates in Blocks 1 and $2(\mathrm{p}<.01)$ but not in Block 3 . Retardates misplaced significantly fewer responses in Trial Block 2 than in Block 1 $(p<.01)$ but did not differ significantly between Blocks 2 and 3. Nonretardates' MPRs did not differ significantly across trials.

\section{DISCUSSION}

Results of this investigation indicate that two sources account for the major portion of all errors made by both retardates and

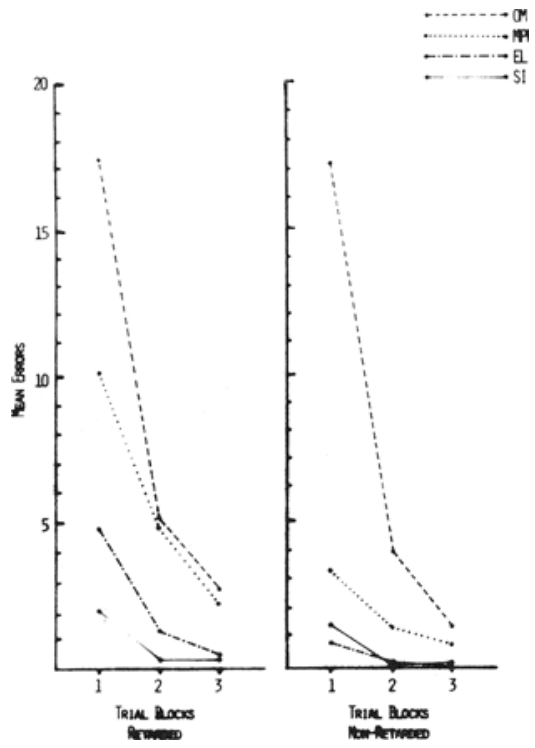

Fig. 1. Mean errors by abject clamification, error type, and trial blocks. nonretardates. Intrusion of stimuli as responses contributes very little to the total error rate and does not seem to account for any difference in learning process by retarded and nonretarded Ss. Similarly, ELI results indicate a substantial frequency only by retardates in the first block of trials. This finding suggests that Underwood and Schulz's (1960) selector mechanism is differentially effective for nonretarded and retarded Ss only in the very early stages of learning. Other $S$ classification differences appear only in MPRs, which showed the greatest difference in early learning. The present data indicate that reduction of $S$ classification differences in acquisition can be expected only by a decrease in ELIs and MPRs. These data also suggest that lowering the frequency of MPRs promises more improvement in learning than ELIs.

OMs and MPRs comprise the largest portion of total errors made by both $S$ groups. These results are in agreement with the findings of Kellas \& Baumeister (1969). The dramatic reduction in OM errors after the first block of trials might suggest that these errors occur as a function of orientation to the task since Ss already knew the responses. Failure to respond is a logical concomitant of learning response time limits and type of behavior required. Support for this speculation is evident in the reduction in rate of decrease from Block 2 to Block 3. Fewer OMs would be expected after the Ss had learned how to respond and the time limits.

MPRs would seem to be errors that are more closely related to the actual associative-leaming process. If this is the case, this type of error should be less dramatically affected by leaming how to perform the task. The present data support this line of reasoning since MPR error-reduction rate is more nearly constant across blocks of trials than OMs.

Results of this investigation might suggest that $O M$ errors reflect orientation to the task parameters. Within the framework of a sequentially constructed model, the stage characterized by $O M$ errors would logically precede the response learning stage in which one might expect extralist intrusion. It would be expected that this response learning stage would be followed by the associative stage in which MPRs were the characteristic error. The present data seem to suggest a considerable overlapping of activities with the orientation and response learning perhaps occurring simultaneously. Inasmuch as most of the variability occurs in the first stages of learning, it might be profitable for future research to investigate this overlap. If the present line of reasoning is correct, a pretask warm-up should result in a greater reduction of OM errors than ELI or MPRs. Further, the response learning stage would seem amenable to analysis by differentiating $S s$ on a response pretest. Error analysis under these conditions would logically show a higher ELI rate for those Ss having the greatest response learning task, i.e., doing less well on the response pretest.

\section{REFERENCES}

DREW, C. J., \& LOGAN, D. R. Extra-list errors in paired associate learning by retarded and normal children. Psychological Reports, in press.

GILLETTE, A. L. Leaming and retention: A comparison of three experimental procedures. Archives of Psychology, 1936, No. 198.

KELLAS, G., \& BAUMEISTER, A. A. Response learning and the paired-associate performance of mental retardates. American Joumal of Mental Deficiency, 1969, 74, 273-278.

PALERMO, D. S., \& JENKINS, J. J. Word association norms. Minneapolis: University of Minnesota Press, 1964.

PREHM, H. J. Rote verbal learning and memory in the retarded. In H. J. Prehm, L. A. Hamerlynck, and J. F. Crosson (Eds.), Behavioral research in mental retardation. Monograph No. 1. Eugene: Rehabilitation Research and Training Center in Mental Retardation, 1968.

UNDERWOOD, B. J. The representativeness of rote verbal learning. In A. W. Melton (Ed.), Categories of human learning. New York: Academic Press, 1964. Pp. 47-78.

UNDERWOOD, B. J., \& SCHULZ, R. W. Meaningfulness and verbal learning. Chicago Lippincott, 1960.

WINER, B. J. Statistical principles in experimental design. New York: McGraw-Hill, 1962. 